\title{
Corrigendum
}

\section{Corrigendum to "Unmet Supportive Care Needs among Breast Cancer Survivors of Community-Based Support Group in Kuching, Sarawak"}

\author{
Emmanuel Joseph Fong and Whye Lian Cheah \\ Department of Community Medicine \& Public Health, Faculty of Medicine \& Health Sciences, Universiti Malaysia Sarawak, \\ 94300 Kota Saramahan, Sarawak, Malaysia \\ Correspondence should be addressed to Whye Lian Cheah; wlcheah@unimas.my \\ Received 11 January 2017; Accepted 27 February 2017; Published 8 May 2017 \\ Copyright (C) 2017 Emmanuel Joseph Fong and Whye Lian Cheah. This is an open access article distributed under the Creative \\ Commons Attribution License, which permits unrestricted use, distribution, and reproduction in any medium, provided the \\ original work is properly cited.
}

In the article titled "Unmet Supportive Care Needs among Breast Cancer Survivors of Community-Based Support Group in Kuching, Sarawak" [1], an incomplete version of Table 5 was incorrectly included. The complete version is shown in Table 5.

Accordingly, the sentence "Respondents with primary education level reported a significantly lower domain mean score compared to those with postsecondary or tertiary education level across the domains of physical and daily living ( 1.71 versus $2.19, p=0.012$ ), sexuality ( 1.33 versus $1.95, p=0.007)$, patient care and support (1.76 versus 2.21 , $p=0.014)$, and health system and information (2.37 versus $3.00, p=0.035$ )" in the Results section should be changed to "Respondents with primary education level reported a significantly lower domain mean score compared to those with postsecondary or tertiary education level across the domains of psychological (1.71 versus 2.19, $p=0.012$ ), sexuality ( 1.33 versus $1.95, p=0.007)$, patient care and support (1.76 versus $2.21, p=0.014$ ), and health system and information (2.37 versus $3.00, p=0.035)$. 


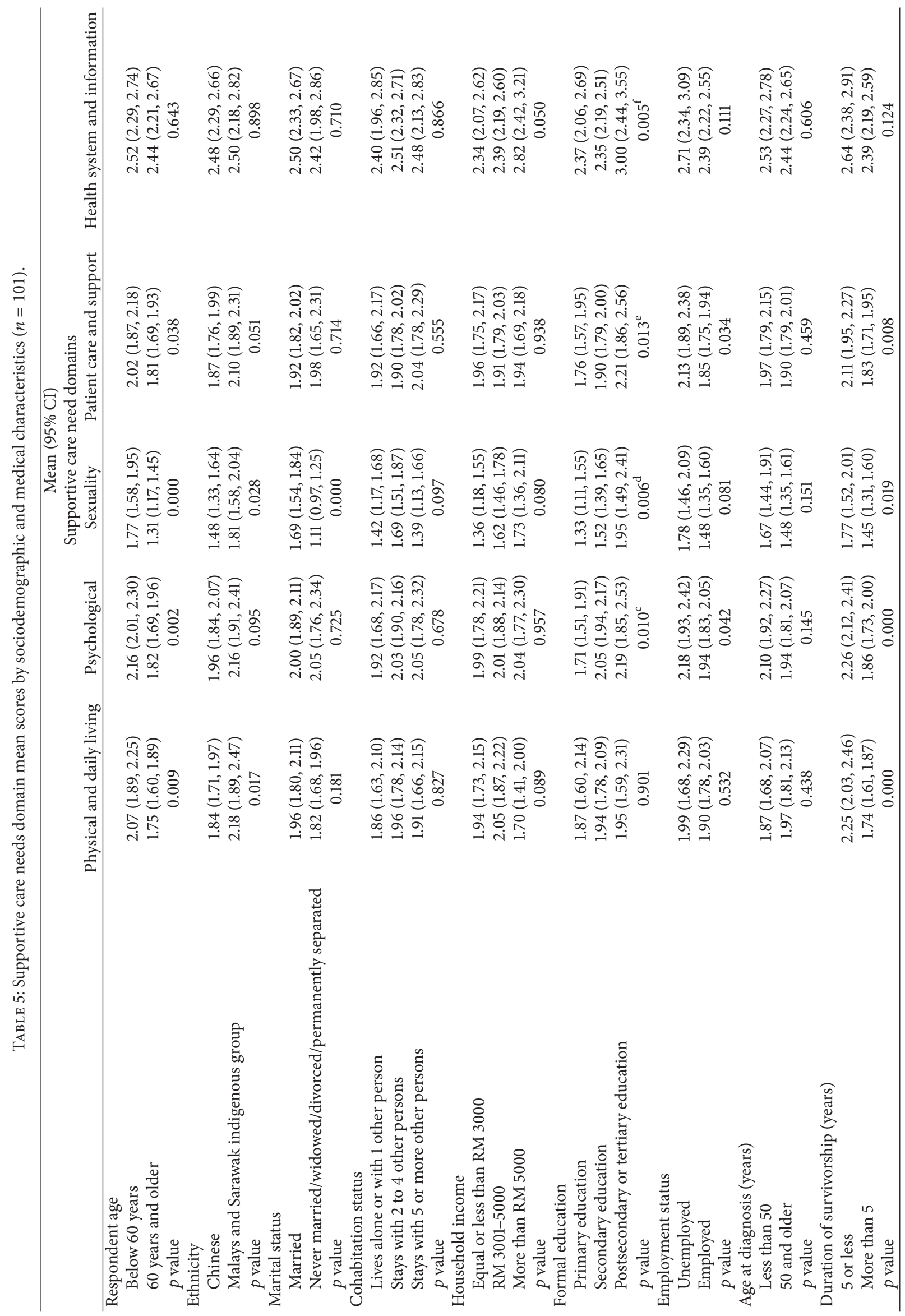




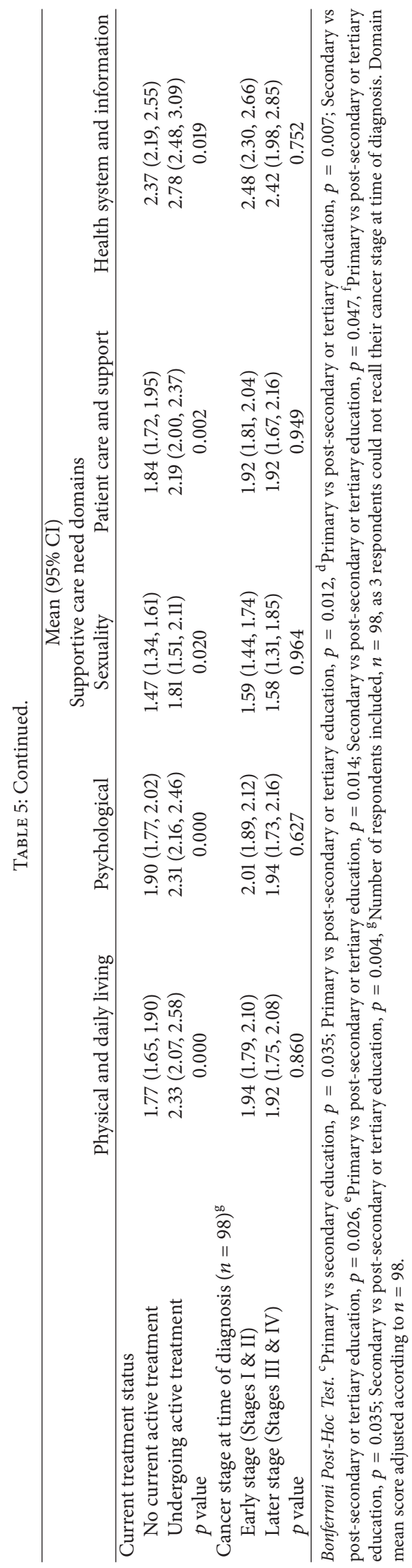




\section{References}

[1] E. J. Fong and W. L. Cheah, "Unmet supportive care needs among breast cancer survivors of community-based support group in Kuching, Sarawak," International Journal of Breast Cancer, vol. 2016, Article ID 7297813, 9 pages, 2016. 


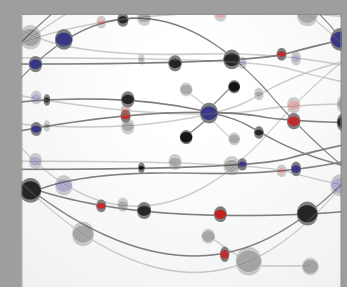

The Scientific World Journal
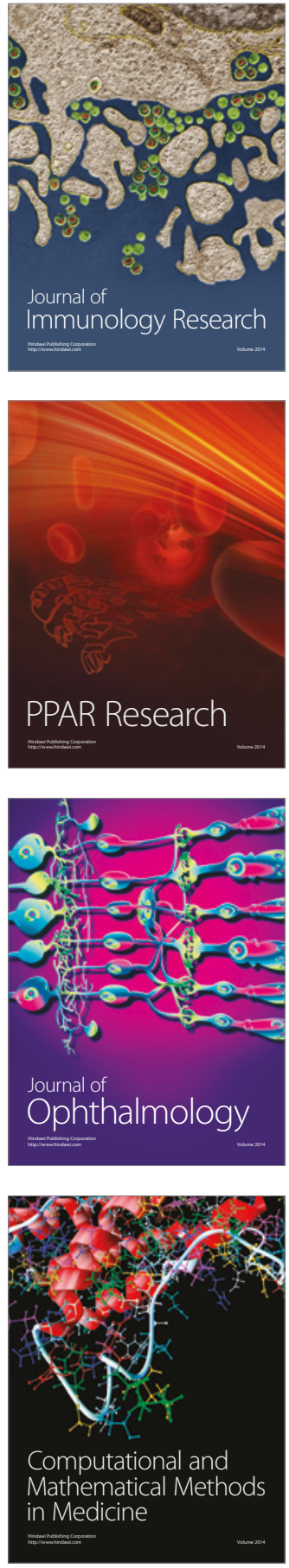

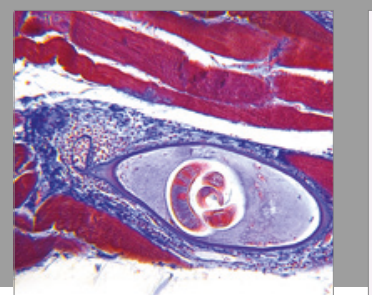

Gastroenterology Research and Practice
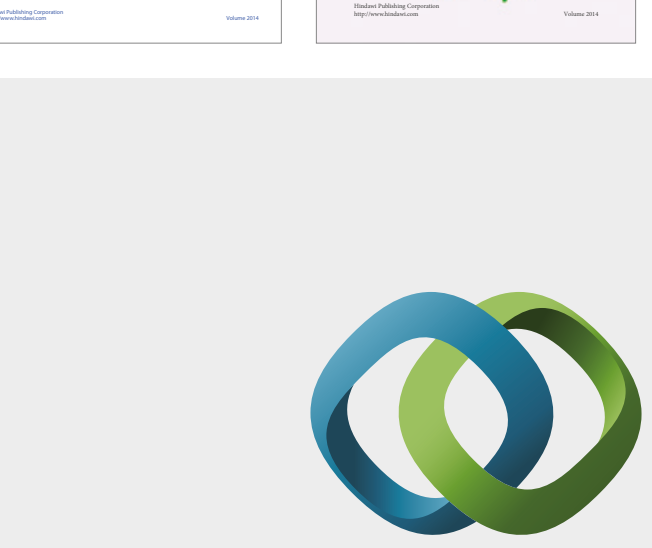

\section{Hindawi}

Submit your manuscripts at

https://www.hindawi.com
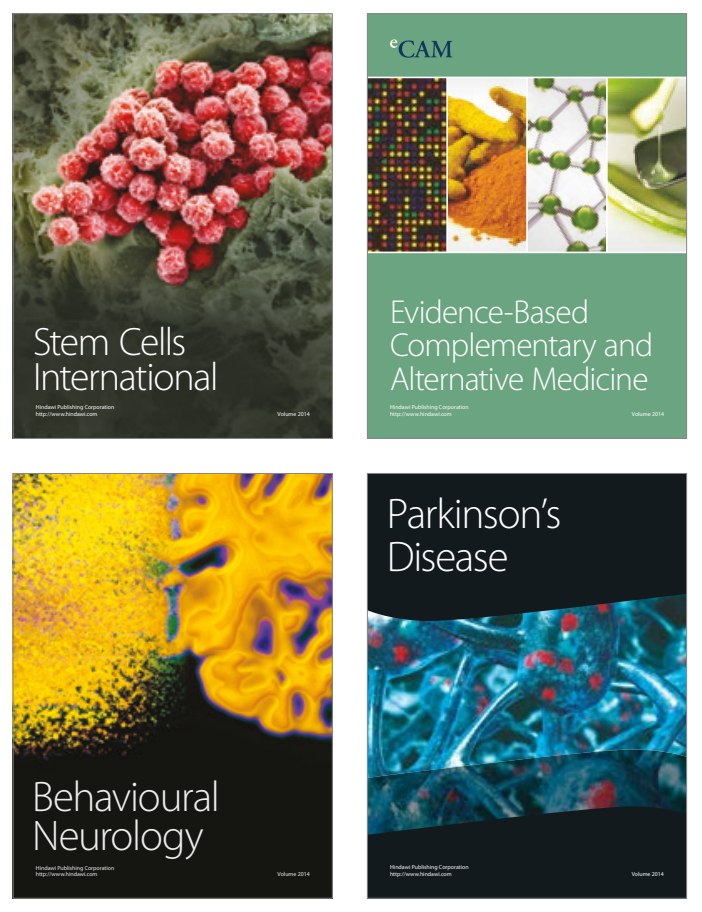
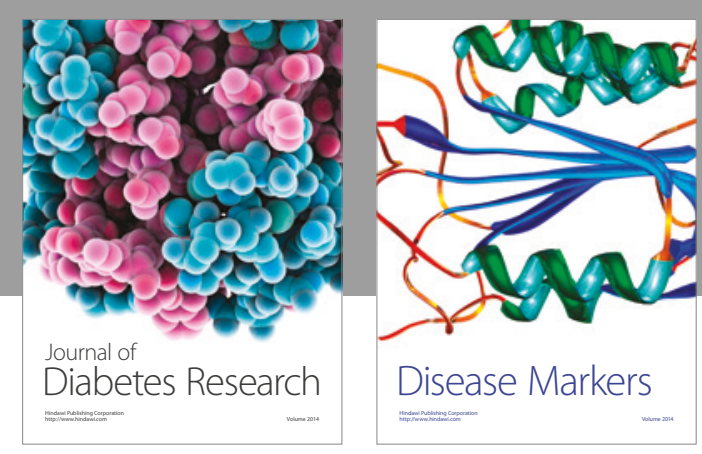

Disease Markers
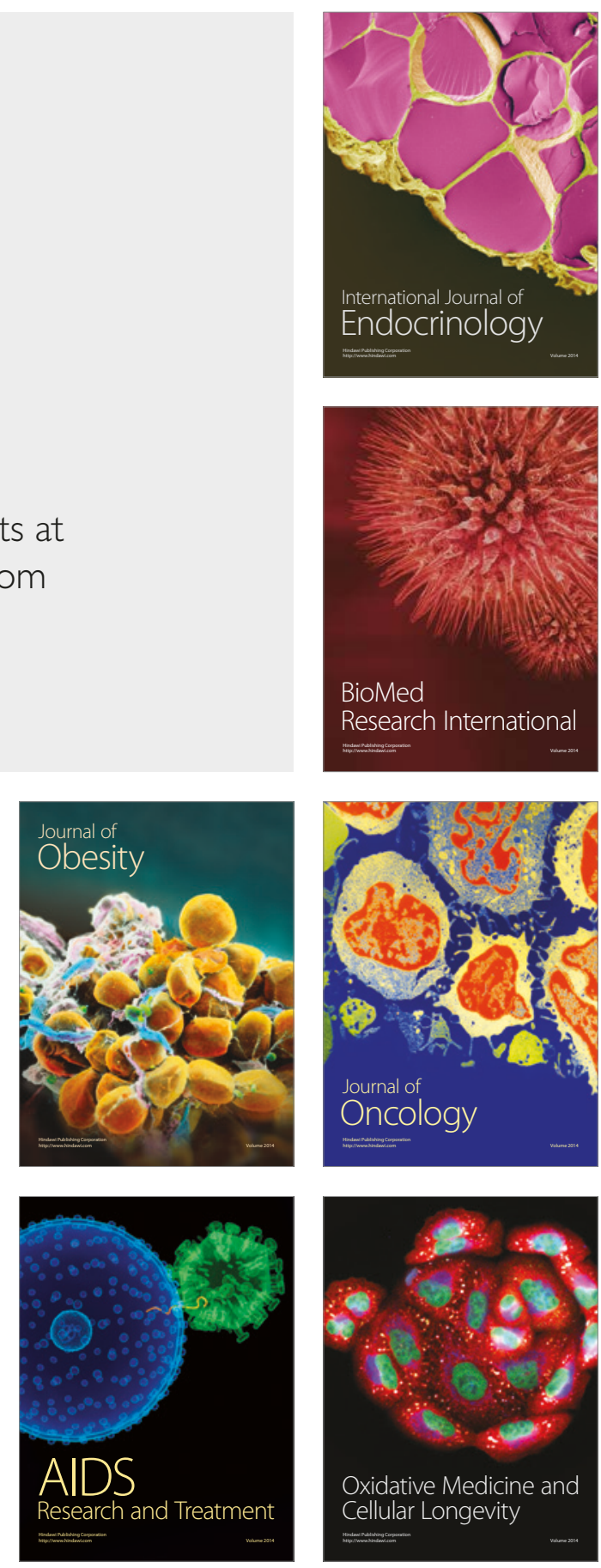